\title{
O dispositivo do Tableau vivant e o gesto em Faz que Vai (2015) de Bárbara Wagner e Benjamin de Burca
}

\author{
Nina Velasco e Cruz' \\ https://orcid.org/0000-0003-1639-5329 \\ I - Universidade Federal de Pernambuco. \\ Recife (PE), Brasil.
}

Resumo: Há uma "vontade de movimento" generalizada nas imagens fotográficas (gifs, boomerangs e vídeos de curtíssima duração são o sintoma mais visível deste fenômeno), assim como uma progressiva estaticidade das imagens em movimento. Esse fenômeno pode ser investigado a partir do uso recorrente e atualizado da prática do Tableau Vivant na fotografia e no cinema contemporâneos, assim como nas práticas híbridas da videoarte. A questão que levanto deriva da percepção deste fenômeno, articulado com o lugar do "gesto" na cultura contemporânea. Se partirmos do pressuposto de que a mecanização progressiva da modernidade resultou no sentimento da perda do gesto, de que maneira a imagem em movimento pode vir a restituí-lo, como nos sugere Agamben? E como as atuais imagens híbridas contemporâneas, no caso aqui o trabaIho Faz que Vai (2015), de Bárbara Wagner e Benjamin de Burca, reatualizam essa questão?

Palavras-chave: gesto; tableau vivant; vídeo-instalação; Bárbara Wagner

Abstract: The apparatus of Tableau vivant and the gesture in Faz que Vai (2015) by Barbara Wagner and Benjamin de Burca - There is a generalized "will to move" in photographic images (gifs, boomerangs and videos of very short duration are the most visible symptom of this phenomenon), as well as a progressive staticity of moving images. This phenomenon can be inves- 
tigated from the recurrent and updated use of Tableau Vivant's practice in contemporary photography and cinema, as well as in the hybrid practices of video art. The question I raise derives from the perception of this phenomenon, articulated to the place of "gesture" in contemporary culture. If we start from the assumption that the progressive mechanization of modernity has resulted in the feeling of the loss of the gesture, in what way can the moving image restore it, as Agamben suggests? And how do the current contemporary hybrid images, in this case the work Faz que Vai (2015), by Barbara Wagner and Benjamin de Burca, actualize this question?

Keywords: Gesture; tableau vivant; video installation; Barbara Wagner

\section{O gesto e as imagens técnicas}

Agamben, em seu ensaio sobre Kommerell, atenta para o fato de que este havia diagnosticado o sentimento de perda dos gestos pelo homem moderno, especialmente o homem burguês. No entanto, o paradoxo apontado por Agamben está no fato de que "uma época que perdeu seus gestos está, por isso mesmo, obcecada por eles" (AGAMBEN, 2015, p. 218). Ele cita, então, exemplos dessa obsessão na literatura, no teatro e, por fim, "do modo mais exemplar", no cinema mudo (Idem, p. 219). O autor não desenvolve essa ideia, que aparece aqui já no final de seu texto, em que busca antes ressaltar as qualidades do crítico e em desenvolver um conceito de gesto a partir de sua relação com a comunicação e com a linguagem.

Já no artigo "Notas sobre o gesto" (2008), Agamben apresenta melhor a relação dos gestos com o advento das imagens técnicas, especialmente a cronofotografia e o cinema,e, de início, afirma: “No cinema, uma sociedade que perdeu seus gestos procura reapropriar-se daquilo que perdeu e, ao mesmo tempo, registrar a perda" (2008, p. 3). Em seguida, retoma a clássica definição de Deleuze do cinema como imagem-movimento, composto não por "poses eternas", nem por "cortes imóveis", mas sim por "cortes móveis", para estender essa definição "a toda imagem moderna". Na verdade, o próprio conceito de imagem deveria ser revisto na modernidade, pois sua "rigidez mítica" teria sido despedaçada e, no lugar da imagem, teríamos apenas gestos.

De fato, toda imagem é animada por uma polaridade antinômica: de um lado, ela é a reificação e a anulação de um gesto (é a imago como máscara de cera do morto ou como símbolo), do outro, ela conserva-lhe intacta a dynamis (como nos instantes de Muybridge ou em qual- 
quer fotografia esportiva). A primeira corresponde à lembrança de que se apodera a memória voluntária, a segunda à imagem que lampeja na epifania da memória involuntária. E, enquanto a primeira vive num mágico isolamento, a segunda envia sempre para além de si mesma, para um todo do qual faz parte. [...] Pois em toda imagem está sempre em ação uma espécie de ligatio, um poder paralisante que é preciso desencantar, e é como se de toda história da arte se elevasse um mudo chamado para a liberação da imagem no gesto. (AGAMBEN, 2005, p. 4).

Se a fotografia e a cronofotografia parecem desvelar aquilo que o olho humano não era capaz de ver no breve instante entre uma pose estática e outra (o inconsciente ótico de Benjamin), o cinema atua desencantando esse poder paralisante da imagem, a liberando enfim, para o gesto latente na imagem estática (seja ela uma escultura, uma pintura ou uma fotografia). No entanto, é importante distinguir o gesto, na concepção de Agamben, de um sentido mais amplo, comum na antropologia, que o entende como quaisquer movimentos corpóreos que tendem a exprimir significados ${ }^{1}$ (AGAMBEN, 2018). Ao tentar definir gesto, pensando-o como um movimento não-expressivo, Agamben sitetiza:

Uma primeira definição - por certo insuficiente - que havia proposto era esta: o gesto não é nem um meio, nem um fim: antes, é a exibição de uma pura medialidade, o tornar visível um meio enquanto tal, em sua emancipação de toda finalidade (AGAMBEN, 2018, p. 3).

É por esse motivo que os primeiros cinemas teriam uma conexão mais direta com o gesto em vias de desaparecer na modernidade. O cinema, em suas primeiras décadas, se caracterizava por um dispositivo cujo principal atrativo era o potencial de seu meio. Tom Gunning (2006), ao rever a história dos primeiros cinemas, demonstra que chamado "cinema de atrações" tem como principal espetáculo o próprio cinema, seu maquinário, e exibição de suas potencilidades técnicas (close-ups, diferentes truques de montagem, slow motion, acelerações do movimento, etc.). Não é pelo fato do cinema apresentar o movimento de forma naturalista (como uma ilusão da duração, como critica Bergson) que faz com que o cinema reconduza a imagem

1 Agamben se refere aos estudos que definem os gestos como "linguagem corporal", como os clássicos autores da antropologia que defendem a ideia de que "o corpo fala". No entanto, no campo da antropologia também podem ser encontradas discussões sobre o caráter involuntário e mimético do gesto, como por exemplo em Marcel Jousse (2008), que se aproximam da ideia de "medialiade pura" defendida por Agamben (CITTON, 2012). 
"à pátria do gesto", mas sim por seu caráter de "medialidade sem fim", ao menos nesse momento originário, não-narrativo.

Ainda na tentativa de uma ontologia do gesto, Agamben cita o coreógrafo Domenico Piacenza, que no século XV defendia o uso de uma pausa na dança, denominada "fantasmata", "uma pausa súbita entre dois movimentos, a ponto de contrair na própria imóvel e petrificada tensão a medida e a memória de toda a série coreográfica" (AGAMBEN, 2018, p. 3) “Decisivo para compreender a natureza do gesto é, assim, o momento da interrupção e da suspensão, isto é, sua relação com o tempo compreendido como sucessão cronológica linear" (Idem, p. 3). Não apenas na teoria da dança, como também na teoria do teatro e da pintura, a questão da interrupção do movimento irá sublinhar o poder expressivo do gesto, seja através da ideia de "instante pregnante" (Lessing) ou nas ideias de "tableaux dramatiques" (Diderot), sobre as quais me deterei a seguir, ao relacioná-las com o que defendo ser constitutivo do "dispositivo tableau vivant".

\section{O dispositivo tableau vivant: o gesto e o movimento suspendido}

A prática do Tableau vivant ${ }^{2}$ remonta à Idade Média, quando pessoas caracterizadas de personagens bíblicos "encenavam" em poses estáticas a cena do nascimento de Cristo na manjedoura, em presépios vivos, na Itália. No entanto, é a partir do século XVIII que esse tipo de encenação aparecerá com mais regularidade, principalmente no contexto da cena teatral, após a grande importância dada a esse recurso dramático por Diderot. Em sua defesa das reformas do Teatro Clássico, Diderot considerava que os atores se dirigiam de forma demasiadamente manifesta ao público, rompendo com seu poder de representação. Para ele, os personagens deveriam atuar como se as cortinas não tivessem sido levantadas, ou diante de uma parede imaginária. É nesse contexto que surgem os tableaux dramatiques: alguns momentos cruciais no drama eram condensados em uma cena estática, remetendo muitas vezes a cenas pictóricas clássicas, buscando efeitos plásticos para o Teatro. Outras funções que esse tipo de encenação possui ainda no século XVIII são a de entretenimento, a partir da reprodução de personagens pictóricos encenados em momentos de lazer, as também chamadas

2 O termo em francês, que quer dizer literalmente "quadros vivos", foi adotado no português e em outras línguas, como o inglês, para se referir a esse gênero dramático. Encontra-se também em alguns textos o termo em alemão Lebende Bilder (imagens vivas). 
"atitudes", nas propriedades de férias da aristocracia francesa e inglesa, e o uso pedagógico por preceptores para reproduzir cenas históricas a alunos da nobreza do Antigo Regime.

Mas será, sobretudo, no século XIX que os tableaux vivants irão se autonomizar e deixar de possuir apenas um caráter auxiliar na cena dramática para se tornar um gênero artístico com múltiplas funções, independente de uma narrativa teatral. Esse gênero, no entanto, vai permanecer de alguma forma com um aspecto secundário (VOUILLOUX, 2012), pois se funda principalmente no reconhecimento, por parte do espectador, da obra de arte precedente a qual faz referência. É por essa razão que esse tipo de espetáculo era destinado, naquela época, principalmente ao público elitizado que possuía as referências artísticas necessárias para obter o prazer do reconhecimento.

No início do século XIX, entretanto, essa prática se populariza e ganha outros aspectos e manifestações menos nobres, atingindo a um público de massa. Os tableaux vivants podem ser arrolados ao conjunto de espetáculos que costumam ser reconhecidos como pré-cinematográficos, como os panoramas e os dioramas. Nesse período, os tableaux vivants chegaram a ser encenados em cabarés e musics halls atingindo um público de classe media, que entendia a prática como mais artistica do que outros espetáculos populares justamente por remeter à iconografia da pintura clássica (WIEGAND, 2018). Com o surgimento da fotografia e do cinema, os tableaux vivants são retomados com novas funções estéticas, especialmente nos primórdios dessas duas linguagens.

Apesar de os tableaux vivants fotográficos terem sido relativamente usuais, especialmente no período pictorialista, e ainda sejam presentes na arte contemporânea, um dos aspectos fundamentais que caracterizam esse gênero se perde aqui: a relação tênue entre imobilidade e movimento. De fato, um tableau vivant nunca é completamente estático, ele se funda em um movimento que se imobiliza e que logo é retomado. Outra característica que se perde na fotografia e que está sempre presente nesse gênero é a percepção por parte do espectador dos movimentos sutis inerentes aos corpos vivos dos atores, como a respiração, o piscar de olhos, os tremores musculares etc. Esses movimentos, que devem ser reduzidos idealmente ao mínimo, muitas vezes são observados como falhas no procedimento, mas exercem também uma fascinação no público, já que asseguram o caráter "vivo" da representação. 
A fotografia se utiliza de sua especificidade essencial, a de fixar um instante preciso, para realizar principalmente três tipos de tableaux vivants: a mera representação de um espetáculo produzido como tal para um público presente; a criação de uma imagem fotográfica que remete a pinturas conhecidas, através da pose e mesmo de fotomontagens; ou ainda a reprodução de cenas pictóricas em fotografias montadas e posadas, como as de Julia Margaret Cameron, por exemplo. Michel Poivert (2010) observa que uma das características da fotografia contemporânea é seu caráter teatralizado, em que a "imagem performada" recusa o caráter instantâneo que caracterizou a fotografia moderna. A prática do Tableau Vivant revela, segundo sua análise, um dos antecedentes que melhor exprimem algo que subsiste na fotografia desde sua origem: sua teatralidade.

Ao se inserir desde o século XVII na estética do teatro e contribuindo a pensar esse último como uma imagem, o tableau vivant forma uma figura até agora não percebida na origem da fotografia. Estética da imobilidade, do silêncio e do 'enquadramento', mas também da reprodução, um tableau vivant é por princípio uma fotografia" (POIVERT, p. 220)

As cenas posadas das primeiras fotografias, comumente explicadas por uma limitação técnica ou por uma excepcionalidade estética, no caso do pictorialismo, poderiam, assim ser reinterpretadas por um regime de imagem que foi minoritário durante o período moderno, mas que sempre existiu na história da fotografia: o regime performático. Para o autor, "performar uma imagem não significa registrar uma performance, mas sim [...] efetuar uma imagem como se efetua um gesto" (POIVERT, 2010, p. 213). Na fotografia contemporânea a imagem performada passa a ter um espaço senão central, certamente não marginal. Ele cita um conjunto de fotógrafos que trabalham atualmente como "metteurs en scène do imóvel" (Idem, p. 221) utilizando direta ou indiretamente o dispositivo do tableau vivant, como Liu Zehng, Joël-Peter Witkin, Jan Saudek, Jeff Wall, Jeff Bark, Gregory Crewdson, Desirée Dorlon, entre muitos outros.

E qual seria a relação, então, do tableau vivant com o cinema? Historiadores do cinema costumam destacar uma referência formal ao tableau vivant no cinema nascente (como é particularmente perceptível nos primeiros filmes narrativos, montados com várias sequências de quadros fixos). Há também os filmes que se propunham a registrar tableau vivants com uma câmera 
fixa, muitas vezes para serem exibidos em casas de vaudevilles onde os espectadores tinham a chance de comparar a representação fílmica com encenações ao vivo (JACOBS, 2011, p.91). Outros autores, como Wiegand (2016), por sua vez, defendem que há uma relação essencial entre os primeiros cinemas e os tableaux vivants. Wiegand (2016) descreve os tableaux vivants dos anos 1900 como sendo um espetáculo elaborado, com jogos de iluminação e encenações. Eles cumpririam, segundo o autor, dois objetivos simultaneamente: apresentavam novas sensações visuais e criavam uma certa concepção de "arte" para os espectadores de uma burguesia emergente. O autor analisa, ainda, uma série de filmes desse período em que o tableau vivant aparece como mais um efeito "atrativo", sem qualquer contexto narrativo. O poder de atração desses dois meios (o cinema e o tableau vivant) se reforçaria mutuamente, nessa época, segundo sua análise.

A aparição de tableaux vivants em filmes modernos não é incomum e alguns dos exemplos mais significativos são os filmes: Passion de Jean-Luc Godard (1982), o episódio dirigido por Pasolini em RoGoPaG (1963), La Ricotta, e L'Hipotèse du Tableau Volé (1978), de Raul Ruíz. Nesses casos, sintomaticamente, os tableaux vivanst aparecem como um recurso metalinguístico e não um recurso narrativo da trama principal3. Relações mais indiretas entre o cinema moderno e o dispositivo dos tableaux vivants podem ser percebidas em diretores como Chantal Akerman, Alain Resnais e Chris Marker, como aponta Jacobs (2011). No cinema contemporâneo, destacamos o filme $O$ Moinho e a Cruz (2011), de Lech Majewski, em que o quadro A Procissão para o Calvário (1564) de Pieter Bruegel é recriado em um grande tableau vivant e o filme Na Ventania (2014), de Martti Helde, em que esse recurso é levado ao extremo, sendo composto quase que exclusivamente com planos-sequência em que os atores se encontram estáticos. Para Koering (2015, p. 310), o que faz com que a presença dos tableau vivant seja algo recorrente ao longo da história do cinema seria justamente uma certa ligação intrínseca entre os dois dispositivos, a partir da relação entre o imóvel e o movente que é fundamental nos dois casos. Enquanto um tableau vivant (ao menos em sua versão mais clássica, a teatral) é formado a partir de um movimento que se imobiliza para ser então retomado, um filme parte sempre de uma imagem estática que se coloca em movimento para depois tornar a ser fixa.

3 Em Passion, os tableaux vivants aparecem em cenas a serem filmadas pelo personagem principal, um diretor de cinema em crise criativa. Em La Ricotta, por sua vez, os personagens fazem parte da filmagem da Paixão de Cristo, encenada em tableaux vivants. O filme de Raúl Ruiz é aquele em que os tableaux têm mais importância narrativa, porém o recurso da metalinguagem é evidente pelo uso de um narrador, que explica cada cena encenada nas sequências estáticas. 
Jacques Aumont, em seu referencial livro sobre a relação entre cinema e pintura, sublinha justamente a questão temporal (causalidade narrativa) em sua relação com o espaço (quadro) como sendo essencial para entender a diferença e a aproximação dessas duas artes. O enquadramento, analisado por Bazin como sendo um elemento diferencial das duas linguagens ${ }^{4}$, é para Aumont aquilo que revela a "filiação subterrânea e essencial" entre o cinema e a pintura e não uma diferença ontológica. No entanto, se podemos perceber "diversos efeitos de quadro" no cinema, assim como "desenquadramentos" na pintura (o caso de Degas, por exemplo, é exemplar), quando se trata da relação com a narrativa, e consequentemente a inserção da causalidade temporal na imagem, a questão se complica. Por mais que a pintura tenha almejado representar de diversas maneiras uma narrativa que se desenrola no tempo, a imobilidade constitui um limite teoricamente intransponível ao quadro pictórico, trazendo uma dificuldade suplementar para encadear uma narrativa imagética. "Narrativa ou menos narrativa, é toda a pintura que se choca com esse intransponível: figurar o tempo" (AUMONT, 2004, p. 81). Para que uma pintura represente uma narrativa completa, ou terá que apresentar uma sequência de quadros, ou buscar a síntese do acontecimento em um instante único, no qual a ação principal da narrativa se encontra condensada.

A dialética entre imagem estática e imagem em movimento é certamente uma das características mais fundamentais do que estamos considerando que seja o "dispositivo tableau vivant". Quando Diderot propõe o uso dos tableaux dramatiques como recurso narrativo, ele certamente estava influenciado pelo conceito de "instante pregnante" criado por Lessing para se referir à função narrativa presente nas pinturas neoclássicas. Para ele, ao pintor caberia escolher o melhor instante, o que contém o gesto pregnante, no acontecimento retratado, já que a representação do tempo seria uma barreira intransponível para a pintura. Esse gesto deveria ser um gesto claro, facilmente legível e que prefigura o momento seguinte (um momento memorável). Esse instante, que poderia também ser chamado de "instante grávido", como atenta Aumont (2004, p. 81), deveria representar "a história no momento em que ela está grávida: o passado acumulado no gesto e o futuro que se prefigura" (VOUILLOUX, 2012).

\footnotetext{
4 A questão do enquadramento aparece no famoso ensaio de André Bazin sobre o filme Van Gogh (1948), de Alain Resnais e é retomada por diversos autores, inclusive por Aumont (2004, p. 111). Para Bazin, enquanto o quadro pictórico seria orientado "para o lado de dentro" (BAZIN, 1991, p.173), criando uma força centrípeta, o cinema criaria forças centrífugas com o que não está em quadro, dialogando sempre com o fora-de-campo.
} 
Roland Barthes, em seu ensaio sobre as relações entre cinema e teatro, intitulado Diderot, Brecht, Eisenstein (1982), já havia retomado a ideia dos tableaux dramatiques de Diderot para relacionar o que ele chama das "artes da dióptrica" (que incluem o teatro, o cinema e a literatura), através da construção de "quadros" (BARTHES, 1982, p, 77). A "mis en scène" (a colocação dos corpos e elementos cênicos em uma cena, como se coloca uma mesa - "a mesa está posta") seria o fundamento dessas artes, mas o que torna possível aproximar a teoria teatral de Diderot, com o teatro épico de Brecht e o cinema eisensteiniano seria justamente a importância que esses deram à ideia de instante pregnante: "O teatro de Brecht e o cinema de Eisenstein são sequências de instantes pregnantes" (Idem, p. 78). Em Brecht, o conceito que sintetiza a ideia de instante pregnante, para Barthes, é justamente o de "gestus social", associado ao famoso efeito de distanciamento brechtiano (efeito esse que seria o grande diferencial estético entre Brecht e Eisenstein). O "gestus social" defendido por Brecht seria o caráter não individual da gestualidade, que sintetizaria as relações sociais intrínsecas nas situações dramáticas representadas em suas peças. Esse gestus, que se difere da ideia de gestualidade, se apresenta através das relações corporais entre os autores na encenação. As personagens, quando performam levando em consideração esse conceito, devem deixar de representar um indivíduo específico e sua interioridade, para tornar visível seu papel mediador na esfera mais ampla a ser representada: as relações sociais que verdadeiramente os movem em cena.

Aqui também é possível perceber a relação entre o tableau vivant e o conceito de gesto de Agamben, que reconhece no conceito de Lessing uma das características do gesto: a tensão carregada de motilidade da pausa gestual. É essa tensão que confere ao tableau vivant seu caráter de "imagem viva", imagem-devir, imagem latente. E nos parece que as imagens híbridas contemporâneas reatualizam essa dialética, possibilitando, nos atravessamentos entre a estaticidade da fotografia e o movimento do cinema, a aparição do gesto do qual nostalgicamente sentimos a perda.

Ao apresentar a ideia de "entre-imagem", Bellour evoca a potência do congelamento da imagem no cinema, chamada por ele "tomada fotográfica do filme" (BELLOUR, 1997, p. 13) e percebe uma coincidência entre a invasão do fotográfico no cinema da virada da década de 60 e as transformações que surgiram com a imagem eletrônica do vídeo nas décadas seguintes. Esse conceito, que pode parecer datado, já que possui quase três décadas (o livro 
foi publicado pela primeira vez em 1990) passa a ter sua acepção renovada na contemporaneidade pelos atravessamentos entre as tecnologias da imagem cada vez mais presentes na contemporaneidade (FATORELLI, 2013). Hoje, estamos diante de uma miríade de possibilidades de hibridizações entre fotografia, cinema, vídeo e digital (entendido aqui como a imagem de síntese, e não como suporte) e falar da especificidade de cada meio se torna anacrônico e pouco produtivo. É nesse contexto que as passagens entre as imagens fixas e as imagens em movimento se proliferam, tanto nas práticas vernaculares (os smartphones estão recheados de aplicativos que transformam pequenos vídeos em fotografias e vice-versa) como nas produções da indústria do entretenimento e nas práticas artísticas. É nesse contexto que o dispositivo do tableau vivant reaparece com uma recorrência significativa.

\section{'Faz que vai' - entre fotografia e vídeo}

Barbara Wagner, fotógrafa brasiliense radicada em Recife, tem tido cada vez mais visibilidade no campo da arte contemporânea mundial, como atesta sua recente participação representando o Brasil na Bienal de Veneza de 2019. Comumente associado ao documental, seu trabalho, no entanto, pode ser inserido na tendência de "imagem performada" descrita por Michel Poivert (2010). A série fotográfica 'Brasília Teimosa' (2005-2007), em que retrata personagens populares da comunidade ${ }^{5}$ cujo nome intitula a série, marcou o início de sua carreira e já apontava para essa relação entre o documental e a ficção, entre a fotografia e o teatro. Não se trata aqui, certamente, de Tableaux vivants strictu senso, mas o caráter explicitamente posado das personagens, a frontalidade do enquadramento, o uso do flash uniformizando a cena e a construção de uma pequena narrativa, nos remetem diretamente a esse dispositivo (Fig. 1 e Fig. 2). Através do movimento interrompido em um gole de cerveja, em um beijo explícito ou num abraço na criança que acaba de sair do mar, uma cena imóvel é construída. Pode-se prever a retomada dos movimentos espontâneos da situação de descontração da qual foram retirados na suspensão da pose, em que os corpos se colocam como uma imagem, interrompendo o fluxo da vida para fixar gestos claros, que depois retomarem seu movimento natural.

\footnotetext{
5 Trata-se do bairro Brasília Teimosa, uma região litorânea de Recife de ocupação popular que nasceu nos anos 1950, à época da construção da capital do país e ganhou esse nome por ter resistido diversas vezes a tentativas de remoção.
} 

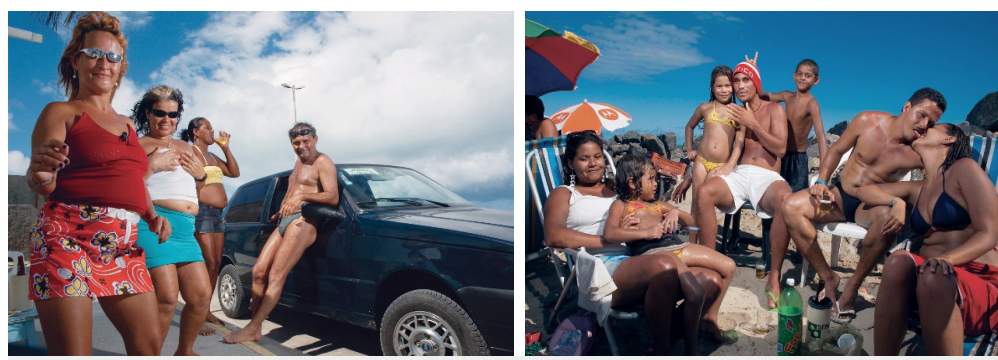

Figs. 1 e 2. Fotografias da série 'Brasília Teimosa' (2005-2007).

Disponível em: https://www.barbarawagner.com.br/Brasilia-Teimosa-Stubborn-Brasilia

A partir de 2011, Bárbara Wagner passa a trabalhar com Benjamin de Burca explorando mais diretamente a interseção entre a imagem fixa e a imagem em movimento. Além das séries de fotografias que continua produzindo, sempre lidando com o universo popular e com o gênero do retrato, Bárbara produz com essa parceria algumas instalações de vídeo em que o corpo e o movimento são colocados em primeiro plano através de retratos audiovisuais. Em 'Cinéma Casino' (2013), por exemplo, a dupla investiga a importância das danças tradicionais e dos ritmos pop na juventude da ilha Reunião, departamento ultramar francês no oceano índico ${ }^{6}$. A instalação é composta por uma projeção em dois canais em que, de um lado, vemos jovens dançando ritmos tradicionais ligados às lutas anticoloniais (Maloye e Sega) e de outro esses mesmos jovens, dançando ritmos internacionalizados e contemporâneos (Zouk, dance, hip-hop, entre outros). Esse trabalho pode ser considerado a semente para a instalação 'Faz que vai', produzida dois anos depois.

Seguindo a lógica de aproximação e contraste das expressões populares tradicionais e contemporâneas, 'Faz que vai' (2015) aproxima o frevo de outros ritmos populares, no caso o funk, a dança vogue, o stilleto e a swingueira. Tendo tido conhecimento de que muitos passistas de frevo profissionais preferiam, em seus tempos livres, dançar ao som de músicas da cultura pop, a artista propôs um dispositivo para um grupo de quatro bailarinos. A proposta era que seus personagens executassem diante da câmera de vídeo uma performance de frevo em diálogo com outro ritmo, sem nenhuma música, apenas com a marcação temporal de um metrônomo (com variações de velocidade para cada um). Na edição, uma música para cada performance foi composta por músicos da Orquestra Popular da Bomba do Hemetério $^{7}$, de forma que se encaixasse com seus passos. Os dançarinos

6 Trabalho comissionado pela $4^{a}$ Bienal de Oceano Índico.

7 Grupo que tem como característica uma atualização e performatização dos ritmos populares de Pernambuco. 
tiveram liberdade de escolher livremente também os adereços e roupas que queriam usar (Fig 3 e Fig. 4).
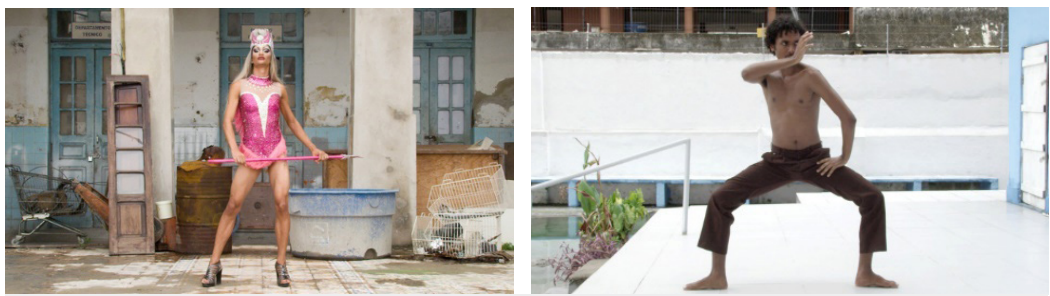

Figs. 3 e 4. Stills de Faz que Vai - Parte 1 Ryan, Frevo e Electro e Parte 2/Edison Frevo e Vogue, extratos disponíveis em https://www.barbarawagner.com.br/Faz-que-vai-Set-to-go

As tomadas partem sempre de um enquadramento aberto em que o personagem ocupa o espaço central, de corpo inteiro. Como em um retrato em movimento, poucos efeitos de montagem são utilizados (alguns zoom in e out, e alguns cortes secos, sobretudo na parte 3). Além dos vídeos, o trabaIho também possui um complemento impresso de quatro fotografias lenticulares, em que a imagem é impressa numa fusão de camadas que causa a impressão de movimento, o que ressalta a importância da relação entre o estático e o movimento nesse trabalho (Fig. 3).

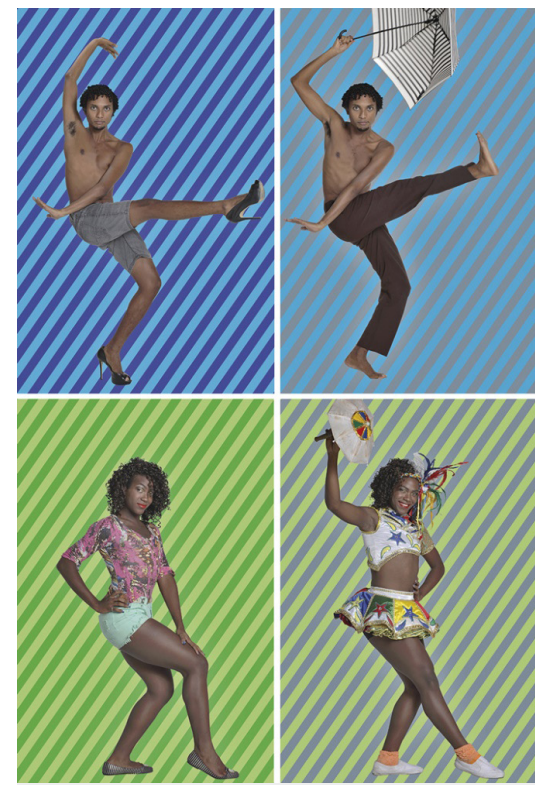

Fig. 5. Fotografias lenticulares que fazem parte da instalação Faz que vai (2015), Bárbara Wagner e Benjamin de Burca 
O título "Faz que vai" remete a um passo de frevo inspirado em um golpe de capoeira. A dinâmica do vai não vai, do drible, do blefe, é encenada em alguns passos de frevo, dança que teve origem no século XIX. Alguns historiadores apontam que o frevo teria surgido em brigas de capoeira entre grupos de escravos que acompanhavam bandas em desfiles militares durante o carnaval. A dança, aqui, assim como no samba das favelas do Rio, surge não apenas como expressão de alegria e espontaneidade, mas também como forma de luta e resistência à condição de marginalidade imposta a certos corpos.

Interessa-nos ainda mais especificamente, a parte 2 encenada pelo dançarino Edison, que aproxima o frevo e o Vogue. O estilo Vogue, por sua vez, nasce na década de 60 em no Harlem novaiorquino, em bailes da cena gay negra americana. Tendo como marca a remissão a poses e ao desfile das modelos de moda (daí o nome Vogue), a dança possui vários momentos de suspensão do movimento, em que o performer transforma seu corpo em imagem. A prática de Vogue segue bastante popular e competições formais acontecem em Ballrooms ${ }^{8}$ em diversas cidades do mundo. $O$ universo do frevo, aparentemente tão distante da dança americana, encontra então nesta dialética estático/movimento e em sua origem de marginalidade e negritude, pontos de convergência. Ambas as danças performam, ao seu modo, um conflito, ou uma maneira de assumir corpos não-hegemônicos, transformando movimentos de uma ação originalmente com uma finalidade (um golpe de luta, um desfile de moda) em um gesto, uma dança, um meio em si.

\section{Considerações finais}

É nesse ponto que podemos dizer que o trabalho de Bárbara Wagner e Benjamin de Burca possui uma dimensão ética e política, do ponto de vista do pensamento de Agamben: “o que caracteriza um gesto é que, nele, não se produz, nem se age, mas se assume e se suporta. Ou seja, o gesto abre a esfera do ethos como esfera mais peculiar do humano" (AGAMBEN, 2017, p. 58). Se Agamben entende a dança como gesto, como meio sem fim, podemos dizer que Faz que Vai ressalta essa medialidade pura, ao sublinhar o caráter gestual e político da dança popular, conectando gestos que possuem raízes no início do século XIX à sua atualização nas danças periféricas contemporâneas. Se o cinema nasce no período em que a burguesia está perdendo

8 Ballroom é o nome das casas de show/dança em que os bailes acontecem. A cena Vogue também é chamada Ballroom e os frequentadores de cada casa costumam adotar o nome da casa em que frequentam e se autodenominam filhos do lugar. 
seus gestos, como afirma Agamben, assim como o Tableau vivant possui seu auge nessa mesma época, isso não quer dizer que os gestos tenham desaparecido. Didi-Huberman, discordando de Agamben, em seu recente trabalho sobre os levantes, argumenta:

\begin{abstract}
Mas fazemos gestos todos os dias, durante todo o dia, sem mesmo nos darmos conta! Não perdemos nossos gestos - quer sejamos burgueses, proletários ou qualquer outra coisa - assim como não perdemos a 'experiência' [...] ou seus desejos inconscientes. [...] Os gestos são transmitidos, os gestos sobrevivem, apesar de nós, apesar de tudo ${ }^{9}$ (DIDI-HUBERMAN, 2016, p. 302).
\end{abstract}

Não se trata aqui, talvez, de um levante, como nas imagens reunidas por Didi-Huberman em sua pesquisa atual. Em Faz que Vai, entretanto, a dança aparece como suporte, resistência, luta, golpe. A frontalidade dos personagens, a maneira que seu olhar se fixa ao espectador, sempre de cabeça erguida, torna evidente o caráter combativo desses corpos que dançam e lutam, ao mesmo tempo. Trata-se de um posicionamento ético e político: um gesto político.

Defendemos a hipótese de que o dispositivo Tableau vivant, atualizado nas formas híbridas entre fotografia e vídeo, sublinha a sobrevivência dos gestos nas imagens contemporâneas. O próprio Agamben enxerga em algumas manifestações da arte contemporânea essa conexão. No ensaio Ninfas, em que reflete sobre a relação entre imagem, tempo e memória, a partir do conceito de Nachleben de Warburg (AGAMBEN, 2012), Agamben se refere à exposição Passions do videoartista Bill Viola como exemplo de um conjunto de imagens em que o tempo se insere nas imagens, atestando o poder de sobrevivência dos gestos nas imagens. Trata-se de um conjunto de vídeos inspirados em quadros do acervo do Getty Museum em que Viola representa, à maneira de tableaux vivants mais ou menos evidentes, cenas pictóricas com movimentos ultra desacelerados, a ponto de fazer parecer ao espectador que se trata de imagens estáticas. Ao analisar especificamente a obra Greetings (que encena a aproximação das personagens femininas de Visitação de Potorno até se fixarem na pose do quadro original), Agamben sentencia: "A cada instante, cada imagem antecipa virtualmente seu gesto futuro e lembra seus gestos precedentes. [...] poderíamos dizer que eles (os

9 Tradução livre da autora. No original: "Mais les gestes on en fait tous les jours, toute la journée, et sans même s'en rendre compte! On ne perd plus ses gestes - qu'on soit bourgeois, prolétaire ou quoi que ce soit d'autre, qu 'on ne perd son 'experience' ou ses désirs inconscientes." 
vídeos de Viola) não inserem a imagem no tempo, mas o tempo nas imagens." (Idem, p. 21). É o caráter secundário do tableau vivant (sua relação direta com uma obra referencial, presente apenas na memória do espectador) que introduz nas imagens uma temporalidade que não depende do movimento, atestando a sobrevivência dos gestos ausentes.

Os exemplos de atualização desse dispositivo são múltiplos e não cessam de se renovar. Podemos citar o filme em 3D feito por Wim Wenders para a exposição Edward Hopper na Fondation Beyeler ${ }^{10}$ e as inúmeras fotografias produzidas por amadores a partir de um desafio proposto no twitter pela equipe de comunicação do Getty Museum ${ }^{11}$, apenas para dar uma noção da diversidade e atualidade do fenômeno. Apontar para essa diversidade e atualidade nos parece relevante para que se perceba a importância e o alcance desse dispositivo nas imagens produzidas na contemporaneidade. Esse artigo, assim, teve como objetivo demonstrar como certos trabalhos, como o da dupla Wagner e Burca, podem ganhar novas interpretações e potências quando vistos à luz desse fenômeno e, sobretudo, através da relação entre esse dispositivo e o conceito de gesto em Agamben.

Nina Velasco e Cruz é professora do Programa de Pósgraduação em Comunicação da UFPE.

ninavelascoc@gmail.com

\section{Referências}

AGAMBEM, G. "Notas sobre o gesto" In: Meios sem fim: notas sobre a política. Belo Horizonte: Editora Autêntica, 2017.

"Kommerell, ou do gesto". In: A potência do pensamento: ensaios e conferências. Belo Horizonte: Editora Autêntica, 2015.

. "Por uma ontologia e uma política do gesto". In: Caderno de Leituras, n. 76, Editora Chão da Feira, abr. 2018.

. Ninfas. São Paulo: Fudação Bienal/Hera, 2012.

ALVIM, L.; CRUZ, N. Na Ventania: do irrepresentável para os tableaux vivants e o uso da voice over. In: Anais do XXVII Compós: Belo Horizonte, MG, 2018.

AUMONT, J. O olho interminável: cinema e pintura. São Paulo: Cosac \& Naify, 2004.

10 Two or three things I know about Edward Hopper, 2019.

11 https://twitter.com/GettyMuseum/status/1242845952974544896 
BAJAC, Q. Tableaux vivants: fantasies photographiques victoriennes (1840-1880). Paris: Éditions des la Réunion des musées nationaux, 1999.

BARTHES, R. L’obvie et l’obtuse: essais critiques III. Paris : Éditions du Seuil, 1982.

BELLOUR, R. Entre-imagens: foto, cinema, vídeo. São Paulo: Papyrus, 1997.

BREWSTER, B; JACOBS, L. Theatre to Cinema. Oforxd: Oxford University Press, 1997.

CAMPAN, V.; MARTIN, M.; ROLLET, S. Qu'est-ce qu ' um geste politique au cinema? Rennes: Presse Universitaire des Rennes, 2019.

CITTON, Y. Gestes d'Humanités: anthropologie sauvage de nos expériences esthétiques. Paris: Armand Colin, 2012.

DIDI-HUBERMAN, G. Soulèvements. Paris: Gallimard/Jeu de Pomme, 2016.

GUNNING, T. Le cinéma d'attractions: le film des premiers temps, son spectateur et I' avant-garde. In: Revue de I'assoctiation française de recherche sur I'Histoire du Cinéma, n. 50, 2006. Disponível em: <https://journals.openedition.org/1895/1242>.

JACOBS, S. Framing Pictures: Film and the Visual Arts. Edimburgh: Edinburgh Film Studies, 2011.

JOUSSE, M. L’Anthropologie du Geste. Paris: Éditions Tel, 2008.

MAIA, A. M. A dança que desafia o retrato. In: Select, ed. 28, 01/03/2016. Disponível em: https://www.select.art.br/a-danca-que-desafia-o-retrato/

POIVERT, M. La Photographie Contemporaine. Paris: Flammarion, 2010.

. Notes Sur I'Image Performée. In: Les Tableaux vivants ou l'image performée. Catálogo co-editado pelo INHA (Institut National d'Histoire de I'Art) e Mare \&Martin, 2015. ROBERT, V. Le tableau vivant chez Raul Ruiz: I' extensions de la perception. In: Decadrages. V. 15, out. 2009, disponível em: <http://decadrages.revues.org/88>.

VERAS, L. Faz que vai: versões para dança do frevo. In: Revista Continente, 01 de junho de 2015.

VOUILLOUX, B. Conferência durante o Nouveau Festival (10/03/2012). Disponível em: $<$ http://www.dailymotion.com/video/xpma89>.

WIEGAND, D. Gebannte Bewegung: tableaux vivants und früer Film in der Kultur der Moderne. Marburg: Schüren, 2016.

. Tableaux Vivants, Early Cinema, and Beauty-as-Attraction. In: Acta Univ. Sapien-

tiae, Film and Media Studies, 15 (2018), p. 9-32.

Artigo recebido em 21/01/2020 e aprovado em 21/05/2020. 